
D:\Nsurg \Vol. 24, No. 1, Jan. - Mar., 2020\Nsurg-2.Doc
Fig. 1-3 Color
(A)
P. $8-14$
III

ORIGINAL ARTICLE

\title{
Operative Technique and Complication Avoidance in Supraorbital Endoscopic Keyhole Craniotomy
}

\author{
MUHAMMAD USMAN, ${ }^{1}$ HAMZA AHMED, ${ }^{3}$ PHILIP E. STIEG ${ }^{2}$ \\ ${ }^{I}$ Department of Neurosurgery " A", Lady Reading Hospital MTI, Peshawar-Pakistan \\ ${ }^{2}$ Department of Neurological Surgery, Weill Cornell Medical College, Cornell University, New York, USA \\ ${ }^{3}$ Liaquat National Hospital and Medical College, Karachi - Pakistan \\ DOI: 10.36552/pjns.v24i1.401
}

\begin{abstract}
Objective: The aim of the current study is to describe the technical details of the endoscopic supraorbital keyhole craniotomy and how to avoid complications related with it.

Material and Methods: In this cross sectional observational study nine preserved human cadavers from The Skull Base Lab of Weill Cornell Medical College, Cornell University, New York, USA were used. Total number of 18 endoscopic supraorbital keyhole craniotomies were performed. Distances between the different targeted anatomical constructs were looked at and measured.
\end{abstract}

Results: A supraorbital craniotomy was performed with details on the technique of the surgery. The second major part of the results comprised of per-operative complications and how to avoid these complications.

Conclusion: To treat anterior and middle skull base pathologies, the endoscopic supraorbital keyhole craniotomy is an effective, valuable and minimal access surgical choice.

Keywords: Supraorbital craniotomy, Minimal access, Complication, Skull base.

\section{INTRODUCTION}

In "Surgery of the Brain and Spine" by author Fedor Krause, described the first supraorbital craniotomy ${ }^{1}$. In the recent years, Neurosurgeons are widely exercising the supraorbital keyhole approach using supraorbital craniotomy. The supraorbital craniotomy was also advocated by Perneczky, et al and other researchers. ${ }^{2,3}$

There are numerous complications due to large conventional craniotomies like; associated with bifrontal, subfrontal, orbito-zygomatic approaches and the eventually better visualization tools, microsurgical techniques, and brain protection have headed to minimal access techniques in the surgery for skull base. These accomplishments have laid down the foundation stone for the keyhole supraorbital craniotomy to address various pathologies of anterior and some middle skull base. ${ }^{4}$

The little craniotomy and broad surgical exposure of the supraorbital technique is the landmark of the surgery, which ultimately fulfils the minimal invasive principle while providing maximally effective outcome, at the same time. The access and wide conception of this procedure can be augmented by endoscopy, that allows improved reach to the areas like; the area beneath the ipsilateral optic nerve (ON), pituitary fossa, contra-lateral parts of the circle of Willis, interpeduncular cistern, anterior third ventricle, temporal lobe, medial aspect of the ipsilateral middle cranial fossa and upper third of the clivus. The ease and flexibility of the keyhole endoscopic supraorbital approach renders it the most efficient and beneficial skull base techniques. ${ }^{3}$

Using the supraorbital approach, beside the reformations to the endoscopic surgery, a variety of anterior fossa skull base lesions surgeries could be treated. ${ }^{5}$ Nevertheless, such extended surgeries are prone to have some devastating post-operative outcome, in the form of, CSF leak or problems in redo 
surgery, due to distorted anatomy. ${ }^{5}$ Consequently, the supraorbital endoscopic keyhole surgery has become a substitute in the treatment of such pathologies, because of its fewer complications and also minimal invasive nature. ${ }^{4,6,7}$

In the contemporary years, a considerable quantity of research has been broad casted on microscopic, endoscopic assisted microscopic or endoscopic supraorbital keyhole surgery to treat anterior and middle fossa skull base lesions. Furthermore, surgical microscopic anatomical details through this approach was studied well. ${ }^{8-16}$ Though, there are insufficient cadaveric studies internationally and up to our knowledge, no study has been previously published in Pakistan so far, related to the endoscopic technique of this procedure. ${ }^{17-20}$ Furthermore, the rationale of our study was to describe the endoscopic supra orbital keyhole craniotomy technique and how to avoid certain potential complications, with measuring the distances in between the targeted anatomical structures.

\section{MATERIAL AND METHODS}

\section{Study Design}

In this cross sectional observational study.

\section{Study Setting}

Nine preserved human cadavers from The Skull Base Lab of Weill Cornell Medical College, Cornell University, New York, USA were used. Ethical approval was sorted out from hospital ethical committee. This study was a part of the fellowship program during June - September, 2015. Total number of 18 craniotomies (endoscopic supraorbital keyhole) were conducted.

\section{Inclusion Criteria}

All available cadaver heads were included.

\section{Exclusion Criteria}

Those with already used the supra orbital area for some other research were excluded.

\section{Operative Technique:}

The endoscope used for this purpose was, $2 \mathrm{~mm}$ diameter and $26 \mathrm{~cm}$ in length rigid endoscope, having $0^{\circ}$ and $30^{\circ}$ lenses (of Karl Storz Gmbh and Co, Tutlingen, Germany). A built in video camera system was used to record all the procedures, that camera system was connected with a screen monitor and photos were acquired by utilizing the "snapshot" option. Different measurements like distance between supraorbital notch/foramen and superior temporal line, for a safe surgical exposure were measured. Furthermore, opening or no opening of frontal sinus was also observed. The target structures to observed were the different contents of anterior and middle fossa base. All data was collected on a pre-designed proforma and was analyzed through descriptive statistics on SPSS version 20.

Certain essential anatomical markers of frontal bone should be taken into account before embarking upon the procedure; superior temporal line, supraorbital foramen/notch and orbital rim. Meticulous consideration should be taken into the account to superficial neurovascular bundle course, especially the supraorbital nerve.

\section{Patient Positioning:}

Supine position should be used. To improve the venous drainage and to ensure gravity related retraction of the frontal lobe, table's head end is raised up to $15^{\circ}$, following that head of the patient is extended slightly with rotation of the head to opposite side with different degrees, which depends upon anatomical goal ${ }^{4}$, as;

- $10^{\circ}-15^{\circ}$ : ipsilateral temporal mesial area, Sylvian fissure and MCA.

- $30^{\circ}$ : lateral suprasellar and retrosellar area with the CN II, ICA and BA.

- $30^{\circ}-45^{\circ}$ : anterior suprasellar region with structures of lamina terminalis and A Com.

- $45^{\circ}-60^{\circ}$ : olfactory groove, planum sphenoidale.

\section{Skin Incision:}

It is given few millimeters lateral to supraorbital notch, in which are running the supraorbital artery and nerve, and the incision extends lateral to the eyebrow. The incision should be on the orbital rim and to elude the frontal numbness post-operatively, it should not cross the supraorbital notch (Figure 2).

\section{Soft Tissue Dissection and Exposure of Bone:}

Next to skin incision, the four stiches or skin hooks were used to retract the skin flaps, thus aids in the exposure of the frontal belly of occipito-frontal and 
other muscles such as temporal and orbicular. Monopolar cautery was used in the direction parallel to the glabella to incise the frontal muscles. Afterwards, the temporal muscle was stripped off from its insertion. Followed by the retraction of the frontal muscle upwards, while temporal muscle laterally, by the help of temporary stiches.Following that, orbicular and frontal muscles gradually be strapped downwards towards the orbit; this step is mandatory to avoid periorbital hematoma post-operatively.

\section{Bony Dissection:}

Beneath the superior temporal line, on the required side of craniotomy, a lateral fronto-basal burr hole was created, by using a drill. Due to the association to the orbit and frontal skull base, meticulous consideration must be carried on to this burr hole. The orbit could be penetrated, with the wrong direction of the drilling, instead of anterior cranial fossa. The dura is then mobilized, followed by sawing of a straight line, in the direction of lateral to medial, parallel to the glabella with the help of craniotome. Afterwards, a bone flap with a height of about $1.5-2 \mathrm{~cm}$ and a width of $2-$ $2.5 \mathrm{~cm}$ is created by sawing a C-shaped line from burr hole to the medial border of the former fronto-basal line. Drilling of inner edge of bone, above the orbital rim is mandatory to obtain the retraction less exposure.

\section{Dural Opening:}

It was done in curved fashion, which the dural base should be towards the supra-orbital rim. Two sutures were used at this stage to retract the free dura edges downwards.

\section{Intradural Work:}

The interior margins of the craniotomy as well as roof of the orbit should be weakened off, with help of drill, in order for providing broader operational angles for operating endoscope. The $2 \mathrm{~mm} 0^{0}$ endoscope was introduced, while retracting frontal pole with $9 \mathrm{~mm}$ brain retractor intradurally, for visualization of the following anatomical structures;

- Optic nerves and the optic chiasm,

- Olfactory tract and the olfactory bulb,

- Both anterior cerebral arteries (A1 \& A2 segments), anterior communicating, bifurcation of the internal carotid artery, middle cerebral artery, anterior choroidal artery and posterior communicating (Figure 2).

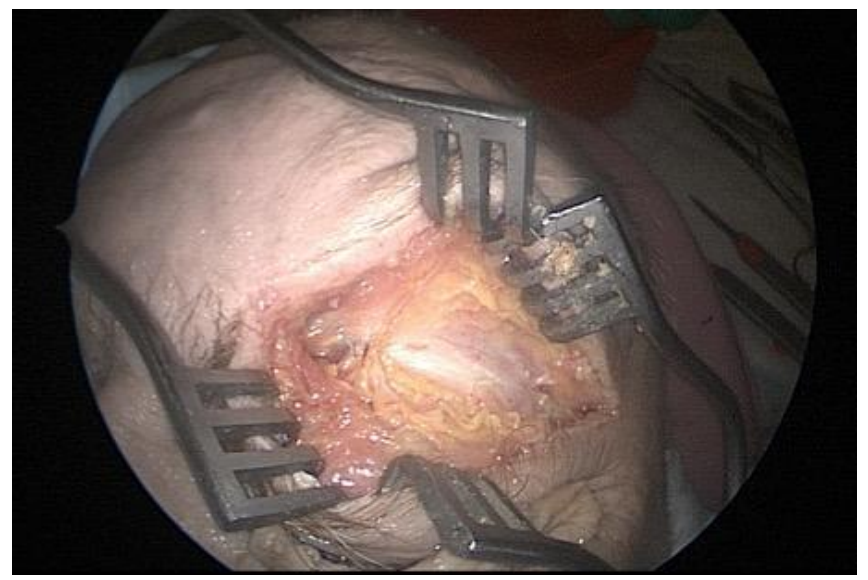

Fig. 1: Incision and Soft Tissue Dissection.

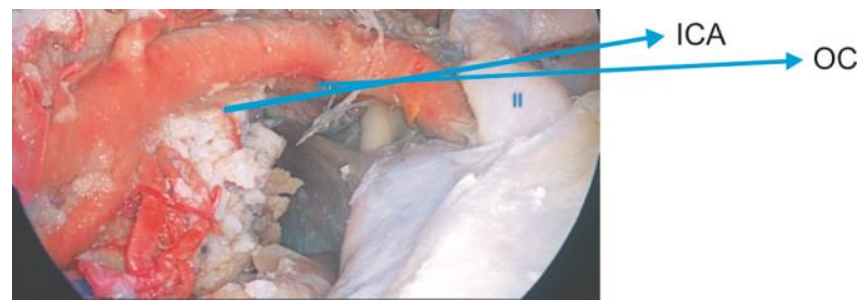

Fig. 2: Anterior and middle skull base - Endoscopic View Key: $I I=$ Optic nerve, $O C=$ Optic chiasm, $I C A=$ Internal carotid artery.

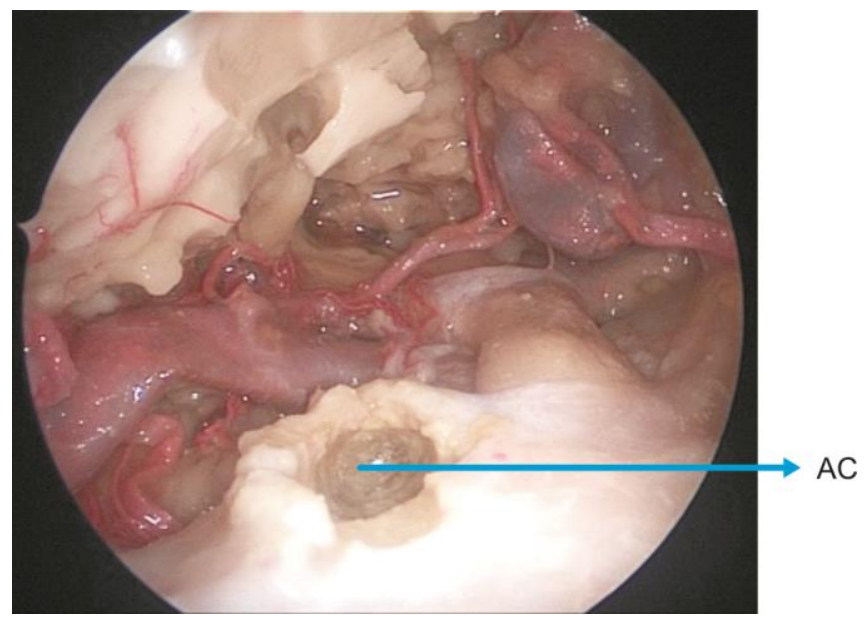

Fig. 3: Anterior Clinoidectomy.

Key: $A C=$ Anterior Clinoidectomy.

By using the $30^{\circ}$ endoscope, diaphragma sellae and infundibulum were visualized. MCA and M2 segment visualized. Between the oculomotor nerve and the bifurcation of the ICA in to the ACA and MCA, the endoscope was introduced into interpeduncular cistern, in order to expose the basilar 
tip, basilar artery, both posterior cerebral arteries and also the posterior communicating artery.

\section{Closure:}

After intradural work, the dura is closed. The careful closure of the frontal sinus should be done with glue and fat, in case of unintended opening. The bone flap issupplanted back and reinforced with titanium mircoplates. Skin is secured with absorbable 3/0 Vicryl. Antiseptic dressing should be applied.

\section{RESULTS}

Total number of 18 craniotomies (endoscopic supraorbital keyhole) were conducted. All available cadaver heads were included. Those with already used the supra orbital area for some other research were excluded.

The second major part of the results was measurement from different anatomical structures to

Table 1: Measurements from STL - SO Foramen.

\begin{tabular}{|c|c|c|c|}
\hline $\begin{array}{c}\text { Cadaver } \\
\text { No. }\end{array}$ & Gender & $\begin{array}{c}\text { Distance from } \\
\text { Rt. STL to SO } \\
\text { Notch (mm) }\end{array}$ & $\begin{array}{c}\text { Distance from } \\
\text { Lt. STL to SO } \\
\text { Notch (mm) }\end{array}$ \\
\hline 1. & M & 33 & 32 \\
\hline 2. & M & 37 & 36 \\
\hline 3. & M & 36 & 35 \\
\hline 4. & F & 34 & 35 \\
\hline 5. & F & 31 & 32 \\
\hline 6. & M & 36 & 35 \\
\hline 7. & F & 33 & 32 \\
\hline 8. & F & 32 & 32 \\
\hline 9. & F & 32 & 28 \\
\hline
\end{tabular}

Table 2: Mean Distance between STL and SO Notch/ Foramen in both sexes and of the Right and Left sides: Data from 9 Cadavers (18 sides).

\begin{tabular}{|l|l|l|l|}
\hline Side & Male & Female & Total \\
\hline Right side & $35.5 \pm 1.73$ & $32.4 \pm 1.14$ & $\begin{array}{l}33.78 \pm \\
2.108\end{array}$ \\
\hline Left side & $34.5 \pm 1.73$ & $31.8 \pm 2.48$ & $33 \pm 2.50$ \\
\hline Total & $\mathbf{3 5} \pm \mathbf{1 . 7 3}$ & $\mathbf{3 2 . 1} \pm \mathbf{1 . 8 1}$ & $\mathbf{3 3 . 3 9} \pm \mathbf{2 . 3 0}$ \\
\hline
\end{tabular}

avoid most common complications, like; injuring of supraorbital neurovascular structures, which causes frontal numbness postoperatively. Table 1 shows measurements from Superior temporal line (STL) to Supraorbital (SO) Foramen. Table 2 shows the mean distance between the SO Notch/Foramen and the STL of the both sides and in both sexes. Opening of frontal sinus was only observed in three sides (Table 3 ).

Table 3: Opening of Frontal Sinus.

\begin{tabular}{|c|l|l|}
\hline Cadaver & Right side & Left side \\
\hline 1. & No & No \\
\hline 2. & Yes & No \\
\hline 3. & No & No \\
\hline 4. & No & Yes \\
\hline 5. & No & No \\
\hline 6. & Yes & No \\
\hline 7. & No & No \\
\hline 8. & No & No \\
\hline 9. & No & No \\
\hline
\end{tabular}

\section{DISCUSSION}

Due to its beneficial effects like, minimal brain retraction, limited surgical exposurebecause of the CSF drainage from the chiasmatic, carotid cisterns and frontal lobe relaxation with gravity related positions, the supraorbital endoscopic keyhole approach is gaining widespread acceptance in skull base surgery. $7,8,14-15,21$ Improved surgical view, shorter hospital stay, satisfactory aesthetic results,prompt recovery, less post-operative pain and economic costs are other advantages. ${ }^{8,14-15}$

There are loads and loads of articles in the literature on microscopic and endoscopic assisted supra orbital keyhole surgery, but very limited data regarding endoscopic supraorbital approach. ${ }^{2,5,7,11,20,22-}$ 24 Contemporary, with the developments in the endoscopic equipment, supraorbital endoscopic keyhole access is also in use to manage the pathologies related to anterior and some middle cranial fossae. ${ }^{4,8,14}$ 15 It is obvious in the literature that endoscopic supraorbital procedure is associated with the least chances of CSF leak asassociated with theother wellknown approach, such as endonasal transsphenoidal extended approaches ${ }^{5}$.Althougha lot ofsubstantial 
studies with respect toendoscopic supraorbital approach are there, but anatomical research is comparatively scarced. ${ }^{12,13,17-20}$ In this cadaveric study, the surgical technique of the endoscopic keyhole supraorbital craniotomy has been explainedand alsohow to avoid common complications by measuring distance between different anatomical structures.

Despite the decent visualization of different structures of anterior and some middle cranial fossa with the endoscopic approach, working beyond basilar tip level is a bit difficult. The endoscope structure may itself sometimes result in iatrogenic injury to important anatomical structures, because of various factors like; narrow surgical corridor and limited proximal control. Consequently, with more clear anatomy and appropriate indications, only few cases would be suitable for this surgical approach, to gain optimum surgical results. Moreover, the majority of the vascular structures, which are inside the cistern of the lamina terminalis, suprasellar cisterns, carotid and chiasmatic cisterns, can be addressed through this approach. This observation is also noted by Alcakaya et al. ${ }^{25}$ The anterior clinoidectomy, which is required to perform certain procedures, can also be done through this technique (Figure 3 ).

In our study, the mean distance between the STL and the SO notch/foramen was $33.39 \pm 2.30 \mathrm{~mm}$. Individually when we see, the distance was somewhat larger in both sexes on the right side and is also more in the males. These findings are compatible with the literature. ${ }^{25}$ However, the current study dictates that there was no considerable difference between both sides in either gender or between the genders. So, to conclude this, we can suggest that the appropriate safe length for the craniotomy is $3 \mathrm{~cm}$ between the STL and the SO notch in both sexes.

A researcher on the same topic, Berhouma et $\mathrm{al}^{4}$ documented that the site and size variability of frontal sinus in any individual, as one of the utmost constraint of the supraorbital endoscopic keyhole approach and recommended that in those individuals in which the frontal sinus crosses/reaches the medial half of the orbit, should be undergone conventional surgery.

In the current study, the opening of the frontal sinus was 3 out of the 18 craniotomies (17\%) and the data is comparable with the former clinical studies $(1.7-15 \%) .{ }^{10}$ Having said that, it should be bear in mind, the opening of the frontal sinusis not always ended with CSF leak, if repair/packing of the frontal sinus is optimum. As Telera et al. testified in his study that there was a frontal sinus opening in $15 \%$ of the cases, but a resultant CSF leak in none of these. ${ }^{10}$ While on the other side, $2.6 \%$ CSF leaks were occurred out of 450 cases in a study by Reisch and Perneczky. ${ }^{11}$ To overcome this problem, the craniotomy extensions could be modified with the help of radiology pre-operatively, as in most of the studies in the literature, the size as well as an extension of the frontal sinus was evaluated pre-operatively.

The limitations of our study are that it comprises of limited sample size and only one ethnic group is studied. To generalize our study findings multi-ethnic studies should be carried on. The strengths of the study are; one of its own kind of study on this issue in a state of the art cadaveric laboratory, well equipped with all the contemporary equipment, meeting international standards. It also laid down a foundation for making more specialized endoscopic instruments for target oriented maneuvers.

\section{CONCLUSION}

The anterior and middle skull base lesions can be approached by endoscopic supraorbital keyhole craniotomy, almost without brain retraction. Furthermore, it addressed pathology completely, because of enhanced visibility by endoscope with the help of its variable angles. Operative instruments could be customized and improved for supraorbital endoscopic keyhole approach, with the help of this study and further research in this domain on fresh cadavers.

\section{REFERENCES}

1. Perneczky A, Reisch R. Keyhole Approaches in Neurosurgery. Volume 1: Concept and Surgical Technique. Wien: Springer-Verlag; 2008: 37 - 96.

2. Reisch R, Perneczky A. Ten-year experience with the supraorbital subfrontal approach through an eyebrow skin incision. Neurosurgery, 2005; 57 (4 Suppl): 242255. Discussion, $242-255$.

3. Reisch R, Perneczky A, Filippi R. Surgical technique of the supraorbital key-hole craniotomy. Surg Neurol. 2003; 59: 223-227.

4. Berhouma M, Jacquesson T, Jouanneau E. The fully endoscopic supraorbital trans-eyebrow keyhole approach to the anterior and middle skull base. Acta Neurochir. 2011; 153: 1949-54.

5. vanLindert EJ, Grotenhuis JA. The combined supraorbital keyhole-endoscopic endonasal transsphenoidal approach to sellar, perisellar and frontal skull base tumors: Surgical technique. Minim Invasive Neurosurg. 2009; 52: 281-6. [PubMed: 20077375]. 
6. Paladino J, Mrak G, Mikliæ P, Jednacak H, Mihaljević D. The keyhole concept in aneurysm surgery--a comparative study: Keyhole versus stand art craniotomy. Minim Invas Neurosurg. 2005; 48: 251-8.

7. Telera S, Carapella CM, Caroli F, Crispo F, Cristalli G, Raus L, et al. Supraorbital keyhole approach for removal of midline anterior cranial fossa meningiomas: A series of 20 consecutive cases. Neurosurg Rev. 2012; 35: 67-83. [PubMed: 21800054].

8. Kabil MS, Shahinian HK. Application of the supraorbital endoscopic approach to tumors of the anterior cranial base. J Craniofac Surg. 2005; 16: 10705. [PubMed: 16327556].

9. Wiedemayer $H$, Sandalcioglu IE, Wiedemayer $H$, Stolke D. The supraorbital keyhole approach via an eyebrow incision for resection of tumors around the sella and the anterior skull base. Minim Invasive Neurosurg. 2004; 47: 221-5. [PubMed: 15346318].

10. Benjamin V, Russell SM. The microsurgical nuances of resecting tuberculum sellae meningiomas. Neurosurgery, 2005; 56 (Suppl): 411-7. [PubMed: 15794838].

11. Czirják S, Szeifert GT. Surgical experince with frontolateral keyhole craniotomy through a superciliary skin incision. Neurosurgery, 2001; 48: 145-50. [PubMed: 11152339].

12. Figueiredo EG, Deshmukh V, Nakaji P, Desmukh P, Crusius $\mathrm{MU}$, Crawford $\mathrm{N}$, et al. An anatomical evaluation of the mini-supraorbital approach and comparison with standard craniotomies. Neurosurgery, 2006; 59(Suppl 2): ONS212-20. [PubMed: 17041490].

13. Cavalcanti DD, García-González U, Agrawal A, Crawford NR, Tavares PL, Spetzler RF, et al. Quantitative anatomic study of the transciliary supraorbital approach: Benefits of additional orbital osteotomy? Neurosurgery, 2010; 66 (Suppl. Operative): 205-10. [PubMed: 20489507].

14. Kabil MS, Shahinian HK. The endoscopic supraorbital approach to tumors of the middle cranial base. Surg Neurol. 2006; 66: 396-401. [PubMed: 17015120].

15. Kabil MS, Shahinian HK. Fully endoscopic supraorbital resection of congenital middle cranial fossa arachnoid cysts: Report of 2 cases. Pediatr Neurosurg. 2007; 43: 316-22. [PubMed: 17627150].

16. Otani N, Muroi C, Yano H, Khan N, Pangalu A, Yonekawa Y. Surgical management of tuberculum

\section{Additional Information}

Disclosures: Authors report no conflict of interest.

Ethical Review Board Approval: The study was conformed to the ethicalreview board requirements.

Human Subjects: Consent was obtained by all patients/participants in this study.

\section{Conflicts of Interest:}

In compliance with the ICMJE uniform disclosure form, all authors declare the following:

Financial Relationships: All authors have declared that they have no financial relationships at present or within the previous three years with any organizations that might have an interest in the submitted work.

Other Relationships: All authors have declared that there are no other relationships or activities that could appear to have influenced the submitted work. sellae meningioma: Role of selective extradural anterior clinoidectomy. Br J Neurosurg. 2006; 20: 129-38. [PubMed: 16801044].

17. Komatsu F, Komatsu M, Inoue T, Tschabitscher M. Endoscopic supraorbital extradural approach to the cavernous sinus: A cadaver study. J Neurosurg. 2011; 114: 1331-7. [PubMed: 21142751].

18. Ciporen JN, Moe KS, Ramanathan D, Lopez S, Ledesma E, Rostomily R, et al. Multiportal endoscopic approaches to the central skull base: A cadaveric study. World Neurosurg. 2010; 73: 705-12. [PubMed: 20934161].

19. Filipce V, Pillai P, Makiese O, Zarzour H, Pigott M, Ammirati M. Quantitative and qualitative analysis of the working area obtained by endoscope and microscope in various approaches to the anterior communicating artery complex using computed tomography based frameless stereotaxy: A cadaver study. Neurosurgery, 2009; 65: 1147-53. [PubMed: 19934974].

20. Komatsu F, Komatsu M, Inoue T, Tschabitscher M. Endoscopic extradural anterior clinoidectomy via supraorbital keyhole: A cadaveric study. Neurosurgery, 2011; 68 (Suppl. Operative): 334-8. [PubMed: 21336210].

21. Jane JA, Park TS, Pobereskin LH, Winn HR, Butler AB. The supraorbital approach: technical note. Neurosurgery, 1982; 11: 537-42.

22. Perneczky A, Müler-Forell W, van Lindert E. Stuttgart, Germany: Georg Thieme Verlag; 1999. Keyhole Concept in Neurosurgery.

23. vanLindert E, Perneczky A, Fries G, Pierangeli E. The supraorbital keyhole approach to supratentorial aneuryms: Concept and technique. Surg Neurol. 1998; 49: 481-90. [PubMed: 9586924].

24. Jallo GI, Benjamin V. Tuberculum sellae meningiomas: Microsurgical anatomy and surgical technique. Neurosurgery, 2002; 51: 1432-40. [PubMed: 12445348].

25. Alcakaya MO, Aras Y, Izgi N, Gayretli O, Sabanci PA, Aydoseli A, et al. Fully endoscopic supraorbital keyhole approach to the anterior cranial base: A cadaveric study. J Neurosci Rural Pract. 2015; 6 (3): 361-368. Doi: 10.4103/0976-3147.154568. 
Address for Correspondence:

Dr. Muhammad Usman

Department, Lady Reading Hospital MTI, Peshawar-Pakistan

Email:drusman387@yahoo.com Mobile: +923339150608

\begin{tabular}{|c|c|c|c|}
\hline \multicolumn{4}{|c|}{ AUTHORSHIP AND CONTRIBUTION DECLARATION } \\
\hline Sr.\# & Author's Full Name & Intellectual/Contribution to Paper in Terms of: & \multirow{4}{*}{$\begin{array}{l}\text { Signature by } \\
\text { the author(s) }\end{array}$} \\
\hline 1. & Muhammad Usman & $\begin{array}{l}\text { 1. Proposed topics and Basic Study Design, methodology. Paper } \\
\text { writing. }\end{array}$ & \\
\hline 2. & Hamza Ahmed & \multirow[t]{2}{*}{ 2. Data collection and calculations\& Results } & \\
\hline 3. & Philip E. Stieg & & \\
\hline
\end{tabular}

Date of Submission: $15-01-2020$

Date of Revision: 31-01-2020

Date of Online Publishing: 25-03-2020

Date of Print: 31-03-2020 